\title{
Análise quantitativa da iluminação artificial e qualitativa da iluminação natural: caso de quatorze bibliotecas
}

\section{Carlos Kazuhiko Hara, André Nagalli*, Annelise Nairne Schamne, Eduardo Leite Krüger, Rodrigo Eduardo Catai, Massayuki Mario Hara e Karina Querne de Carvalho}

Universidade Tecnológica Federal do Paraná (UTFPR). Rua Deputado Heitor de Alencar Furtado, 5000. Bairro CIC. Curitiba-PR, Brasil (CEP 81280-340). *E-mail: nagalli@utfpr.edu.br.

Resumo. Quatorze bibliotecas universitárias foram investigadas, especificamente em suas áreas de acervo e de leitura. Foram realizadas leituras de iluminância destes ambientes quanto à iluminação artificial, tendo sido avaliados através dos Requisitos Técnicos da Qualidade do Nível de Eficiência Energética para Edifícios Comerciais, de Serviços e Públicos (RQT-C), e conforme a norma brasileira de iluminação de interiores NBR ISO/CIE 8995-1. Foram criadas maquetes eletrônicas das edificações visando a simular contribuição de luz natural e a analisar entrada de ganhos diretos de radiação solar no interior das bibliotecas. Adicionalmente, dados de radiação solar incidente foram contrastados com o desconforto causado pelo ofuscamento da visão de usuários. Os resultados mostraram que os sistemas de iluminação apresentaram pequenos desvios a serem corrigidos, oportunizando soluções de retrofit. As análises demonstraram que os sistemas de iluminação das bibliotecas estudadas possuem baixo desempenho. Apenas oito ambientes de acervo e um ambiente de leitura obtiveram iluminâncias médias superiores ao recomendado. No que toca à incidência da radiação solar direta no interior das edificações (carga térmica), o controle da incidência mostrou-se necessário para manter o conforto luminoso e se evitar depreciação do acervo.

Palavras-chave: Bibliotecas; RTQ-C; Sistemas de iluminação; Eficiência energética.

Abstract. Quantitative analysis of artificial lighting and qualitative analysis of natural lighting: Case of fourteen libraries. Fourteen university libraries were investigated, specifically in the areas of collection and reading. In these environments, illuminance readings were performed for artificial lighting, which were evaluated by means of the Technical Requirements for the Quality of Energy Efficiency Level for Commercial Buildings, Services and Public Buildings (RQT-C), as well as the Brazilian standard of interior lighting NBR ISO/IEC
Recebido

$09 / 10 / 2020$

Aceito

$20 / 12 / 2020$

Disponível on line

$23 / 12 / 2020$

Publicado

$31 / 12 / 2020$

Acesso aberto

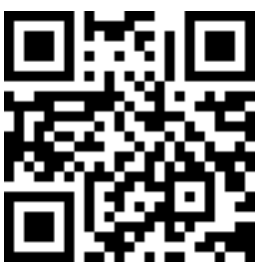

(D) 0000-0001-8988-9771 Carlos Kazuhiko Hara

D 0000-0002-3985-755X André Nagalli

D) 0000-0002-5684-6246 Annelise Nairne Schamne

0000-0003-2895-5530 Eduardo Leite Krüger

ISSN 2359-1412/RBGAS-2020-0155/2020/7/17/36/1601

Rev. Bras. Gest. Amb. Sustent.

http://revista.ecogestaobrasil.net 
8995-1. Building electronic models were created to simulate the contribution of natural light by analyzing the direct input of solar radiation into the libraries. Additionally, the incident solar radiation data were contrasted with the discomfort caused by the glare to which the users are exposed. The results showed that the lighting systems have small deviations to be corrected, providing retrofit solutions for these cases. The research indicates that the lighting systems of the studied libraries present poor performance. Only eight library environments and one reading environment have achieved average illuminances above the recommended level. In relation to the incidence of direct solar radiation inside the buildings (thermal load), the incidence control is necessary in order to maintain the luminous comfort as well as to avoid depreciation of the collection.

Keywords: Libraries; RTQ-C; Lighting systems; Energy efficiency.
0000-0002-6595-8581

Rodrigo Eduardo Catai

(1) 0000-0003-0431-3816

Massayuki Mario Hara

(D) 0000-0003-4577-7537

Karina Querne de

Carvalho

\section{Introdução}

Por suas extensões educacional e intelectual, a bibliotecas revelam-se reflexos da realidade na qual estão inseridas (Leitão, 2005; Souza, 2010). Habitualmente se tratam de instituições sem fins lucrativos e que dependem da organização que as mantém, seus responsáveis por investimentos de manutenção de seu espaço físico e restauração, conservação e aquisição de exemplares, independentemente de sua forma de administração, se pública ou particular (Amaral e Fortes, 2004; Souza, 2010). As bibliotecas universitárias usualmente possuem como mantenedores as próprias instituições a que estão vinculadas, e sua política de investimentos e manutenção e correlata às políticas institucionais (CLIR, 2008).

A função acadêmica de uma biblioteca extrapola a função de disponibilizar livros, sendo espaço no ambiente escolar dotado de função social. Em 1948, bibliotecários, arquitetos e engenheiros pesquisaram o modelo conceitual arquitetônico adequado à edificação de bibliotecas universitárias, sendo este ainda utilizado como referência, apensar das novas tecnologias surgidas (Lucker, 1994).

As bibliotecas tradicionais são locais em que se armazenam e disponibilizam a usuários livros, periódicos e publicações científicas. Nestes ambientes de bibliotecas usuários podem realizar consultas in loco ou ainda realizar empréstimos. Para consultas in loco, o ambiente requer cuidados relativos ao bem-estar dos usuários e à preservação do acervo, em especial características de iluminação, temperatura ambiente e níveis de ruído, vez que influenciam diretamente os usuários (Sousa, 2012). Nestes acervos, danos estão principalmente relacionados à oxidação do papel e de seus pigmentos. Podem ocorrer processos de descoloração, amarelamento ou escurecimento em razão do enfraquecimento e do enrijecimento das fibras de celulose que constituem o papel. Ocorrem alterações de tons e cores prejudicando sua aparência, no caso dos pigmentos (Ogden, 2001).

Os projetos de iluminação e de uso da luz natural em edificações de bibliotecas são requisitos para propiciar a usuários um ambiente confortável, sem prejuízo o acervo. A busca pelo equilíbrio é importante no que concerne à intensidade da iluminação artificial e à melhor utilização da iluminação natural, e, sobretudo, devem ser observados cuidados atinentes ao ofuscamento causado pelas fontes de luz e/ou reflexos que podem causar desconforto. 
Esta investigação teve como objetivo avaliar quantitativamente a utilização da iluminação artificial e qualitativamente a incidência de radiação solar direta em áreas de acervo e de leitura em quatorze bibliotecas universitárias, localizadas em diferentes municípios do Estado do Paraná, utilizando-se como parâmetros recomendações da NBR ISO/CIE 8995-1:2013 (ABNT, 2013) juntamente com o Regulamento Técnico da Qualidade para o Nível de Eficiência Energética de Edifícios Comerciais, de Serviços e Públicos (RTQ-C) e conceitos de conforto luminoso.

\section{Materiais e métodos}

A investigação foi realizada em quatorze bibliotecas (Tabela 1) da Universidade Tecnológica Federal do Paraná (UTFPR), sendo a biblioteca mais antiga localizada na sede do Câmpus D (Curitiba), inaugurada em 1976, e a mais recente inaugurada em 2015, no Câmpus K. Neste cenário, além do intervalo de quase quatro décadas, as edificações foram construídas em três zonas bioclimáticas diferentes (Z1, Z2 e Z3) e os projetos de iluminação artificial atualizados, tendo-se buscado a eficiência energética das edificações. Contudo, até então, a eficiência energética do sistema de iluminação das bibliotecas da universidade em análise não havia sido avaliada, de forma a se verificar seu desempenho, tomando-se por base os padrões atuais sugeridos por normas e programas de qualidade no uso da energia em edificações.

Tabela 1. Localização das bibliotecas estudadas

\begin{tabular}{|l|c|c|c|c|}
\hline Câmpus/Município & $\begin{array}{c}\text { Alunos } \\
\text { matriculados }\end{array}$ & $\begin{array}{c}\text { Área da } \\
\text { biblioteca } \\
\mathbf{( m}^{\mathbf{2}} \mathbf{)}\end{array}$ & $\begin{array}{c}\text { Edificação de } \\
\text { uso exclusivo }\end{array}$ & $\begin{array}{c}\text { Projetada para ser } \\
\text { uma biblioteca }\end{array}$ \\
\hline Apucarana & 657 & 344 & Não & Sim \\
\hline Campo Mourão & 1.788 & 442 & Não & Nã \\
\hline Cornélio Procópio & 1.964 & 725 & Não & Sim \\
\hline Curitiba - Sede Centro & \multirow{2}{*}{8.644} & 1341 & Não & Sim \\
\cline { 1 - 3 } Curitiba - Sede Ecoville & 929 & 522 & Sim & Não \\
\hline Dois Vizinhos & 480 & 151 & Não & Sim \\
\hline Francisco Beltrão & 324 & 557 & Não & Sim \\
\hline Guarapuava & 970 & 415 & Sim & Sim \\
\hline Londrina & 1.958 & 467 & Não & Não \\
\hline Medianeira & 3.125 & 1996 & Sim & Sim \\
\hline Pato Branco & 118 & 152 & Não & Não \\
\hline Santa Helena & 2.416 & 1351 & Sim & \\
\hline Ponta Grossa & 802 & 368 & Não & \\
\hline Toledo & & & & \\
\hline
\end{tabular}

Fonte: UTFPR (2014).

Para a pesquisa foram coletados dados de iluminância dos ambientes de acervo e de leitura das bibliotecas, bem como confeccionados modelos tridimensionais, realizadas simulações de entrada da radiação solar direta no interior de cada edificação e analisados os dados obtidos.

Os recursos utilizados para o levantamento de dados foram projetos arquitetônicos de instalações elétricas e a averiguação in loco das edificações onde estão instaladas as bibliotecas da universidade estudada. Os resultados foram utilizados para 
propor alterações nas edificações (por meio de retrofit) visando a melhorar o sistema de iluminação e a servir de subsídio para futuros projetos.

\section{Iluminação artificial}

Nos ambientes de leitura das bibliotecas estudadas considerou-se que as áreas de trabalho são as mesas de estudos, as quais não possuem um local fixo, podendo ser alteradas pelos próprios usuários. Em virtude desta particularidade, considerou-se que a área de trabalho são os limites da sala, sem deduzir qualquer zona marginal. Este fator implicou em utilizar o limite da uniformidade em $60 \%$ da iluminância mantida.

$\mathrm{Na}$ avaliação do índice de ofuscamento das luminárias, a dificuldade de consultar todos fabricantes de luminárias encontrados nos ambientes estudados, fez com que este índice fosse avaliado qualitativamente. A avaliação baseou-se no fato das lâmpadas estarem expostas à visão direta do usuário ou não, caracterizando-as como luminárias sem ofuscamento ou propícias ao ofuscamento.

A NBR ISO/CIE 8995-1:2013 (ABNT, 2013) define que os pontos de medição da iluminância devem ser os mesmos utilizados no projeto e que as medições realizadas não poderão ser inferiores aos valores calculados para o mesmo ponto.

Porém, os projetos de instalações elétricas das bibliotecas estudadas não possuem os memoriais de cálculo luminotécnico disponíveis. Desta forma, a malha de pontos de medição adotada foi calculada novamente na área de acervo e leitura.

\section{Medição das iluminâncias}

Os locais de cada medição de iluminâncias foram marcados de acordo com os pontos definidos nas malhas de cálculo. Alguns cuidados foram observados para que as medições fossem fielmente transcritas para uma planilha de medições, como por exemplo:

A medição da iluminância realizada por um luxímetro da marca Icel, modelo LD-550, número de série 000098, com certificado de calibração 187315.

Durante a medição, foram utilizadas roupas escuras pelo pesquisador para que não ocorresse reflexão que interferisse no sensor.

Todas as medições foram realizadas após o pôr do Sol, quando a iluminação natural não pudesse interferir.

0 processo de leitura do luxímetro foi realizado de forma não causar sombreamento no sensor, com o pesquisador abaixo do campo de detecção do sensor.

Todas as luminárias foram ligadas pelo menos 10 min antes da primeira medição, garantindo assim um fluxo luminoso pleno das lâmpadas fluorescentes.

Os pontos que coincidiram com elementos estruturais, paredes de alvenaria ou divisórias não foram marcados, entretanto na planilha de cálculo, o espaço reservado para a anotação do valor medido ficou em branco.

A altura do plano de trabalho padronizado em todas as bibliotecas é de $80 \mathrm{~cm}$ em relação ao piso. Para garantir essa linearidade no plano de trabalho, optou-se pelo uso de um tripé utilizado em equipamentos fotográficos para servir de suporte do luxímetro.

\section{Tratamento de dados medidos}

Após a coleta de dados, as informações foram transcritas para uma planilha eletrônica. Este procedimento permitiu o cálculo da iluminância média ( $\left.{ }^{-} \mathrm{E}\right)$ através da média aritmética de todos os pontos medidos. Duas médias foram calculadas neste procedimento, uma representa a iluminância média da área de acervo e a outra da área de leitura.

Os dados da planilha foram convertidos em gráficos para facilitar análise das condições de iluminância encontradas nas bibliotecas. As Figuras 1 e 2 mostram respectivamente as leituras realizadas nas áreas de leitura e acervo da biblioteca do 
Câmpus F. No eixo x são ordenados cada ponto de leitura, o eixo y é graduado com valores de iluminâncias, em lux. Os dados representados nos gráficos são:

- E (lux) - Valor medido da iluminância em cada ponto da malha;

- E (lux) - Valor médio da iluminância da área;

- $\quad$ E 60\% (lux) - Valor limite de 60\% da iluminância média recomendado para manter a uniformidade da iluminação;

- $\quad$ E n. (lux) - Valor da iluminância prescrito pela norma para área de trabalho.

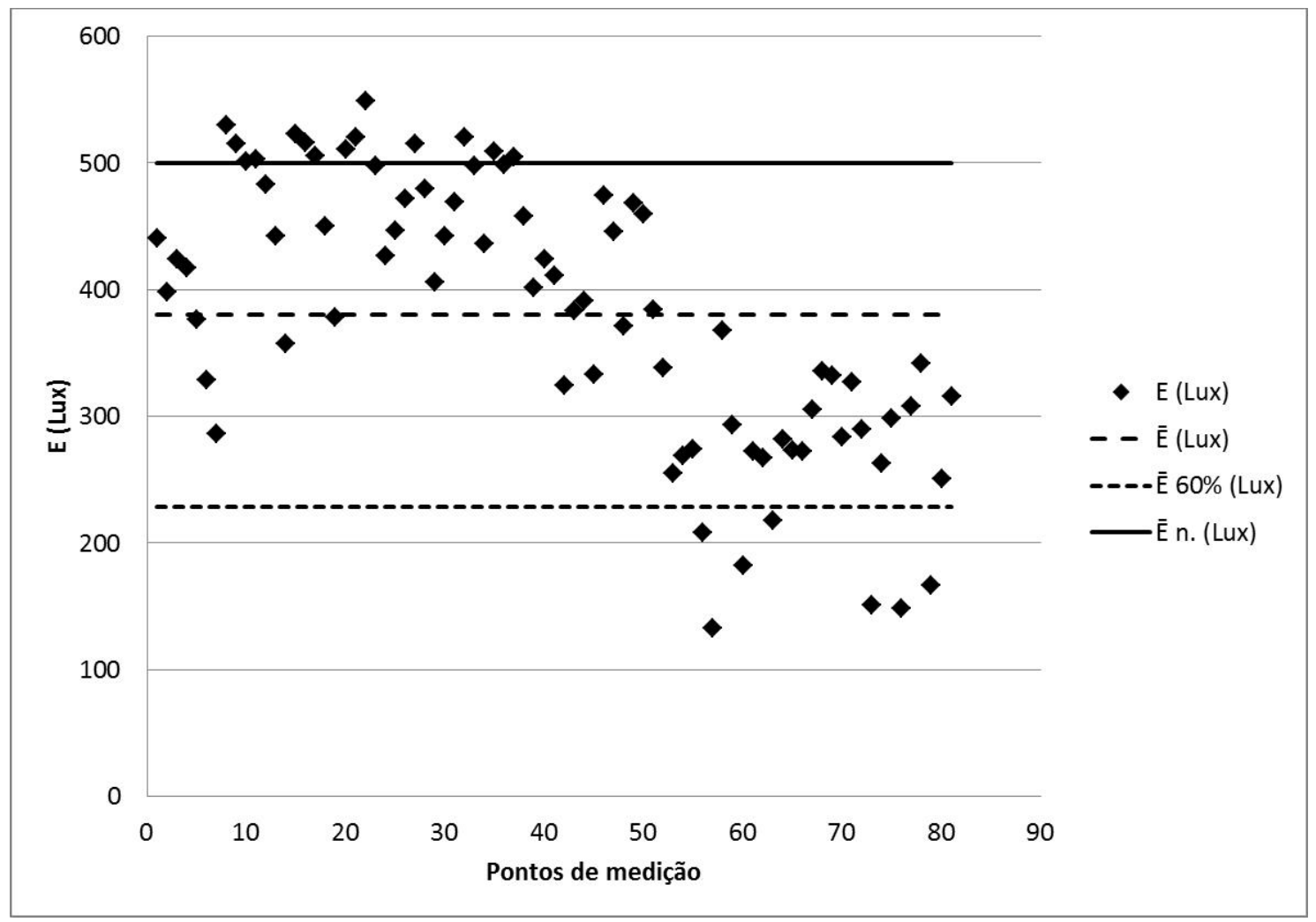

Figura 1. Iluminâncias da área de leitura da biblioteca Câmpus F.

Na Figura 1, constata-se que apesar de existirem pontos medidos acima da iluminância mantida definida pela norma, a média calculada não chega ao nível solicitado. Da mesma forma com relação à uniformidade da iluminação, alguns pontos estão abaixo do valor limite recomendados.

Já na Figura 2, a iluminância média chegou a um nível satisfatório para área de acervo, entretanto diversos pontos obtiveram valores de iluminância inferiores ao recomendado para garantir a uniformidade. A distribuição da iluminância nos ambientes é representada na Figura 3 pelas curvas isolux. Em que é possível observar as áreas de maior iluminação e áreas de sombreamento existente no acervo. 


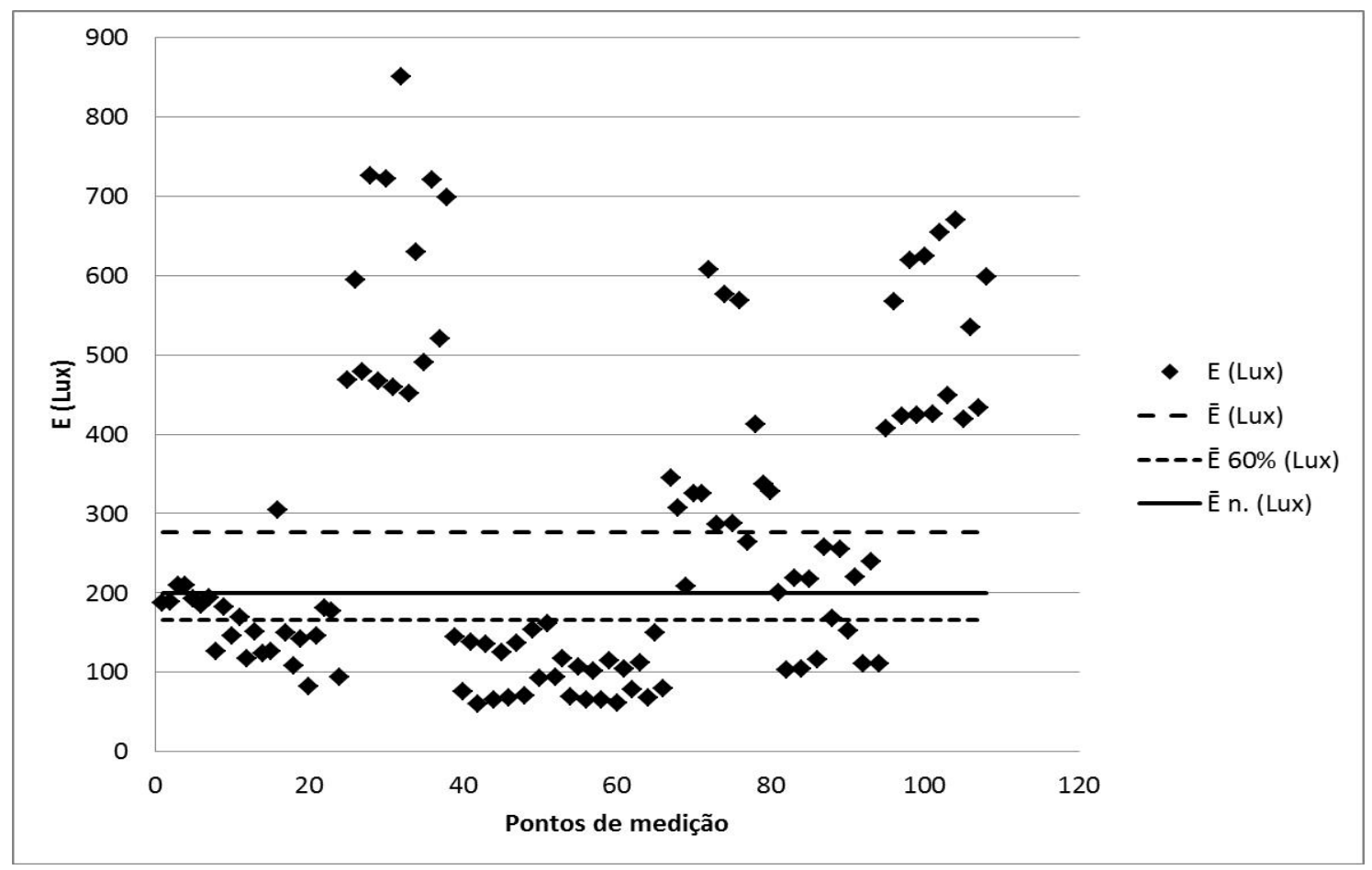

Figura 2. Iluminâncias da área de acervo da biblioteca Câmpus F.

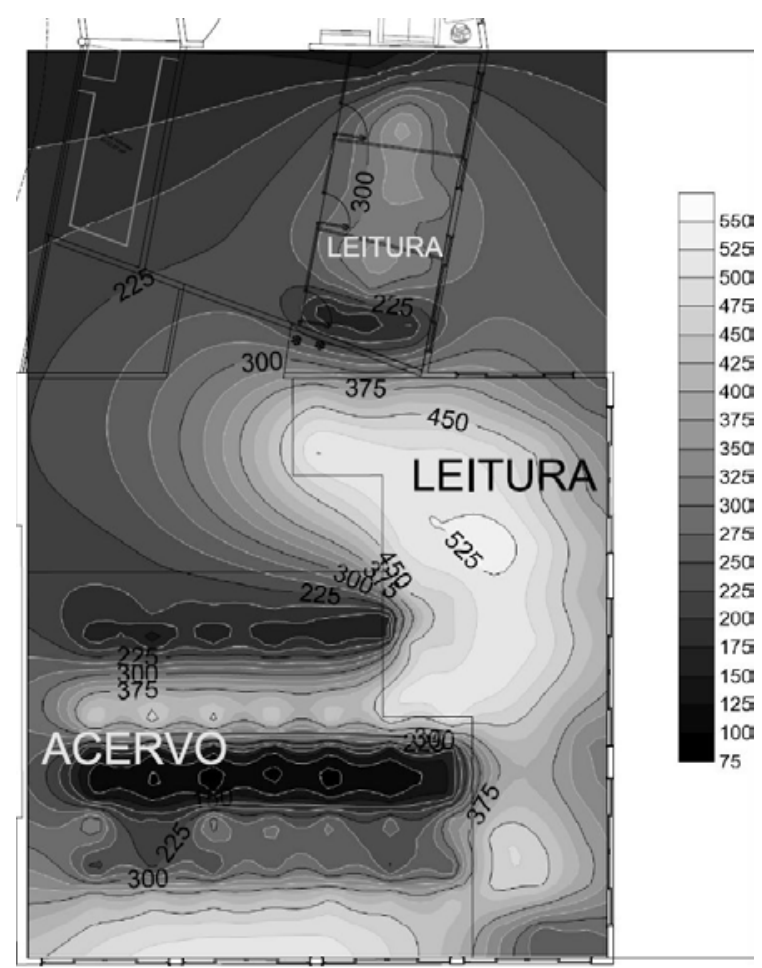

Figura 3. Curva isolux da biblioteca do Câmpus F. 


\section{Parâmetros de avaliação da iluminação - RTQ-C}

A avaliação do sistema de iluminação pelo RTQ-C representa $30 \%$ na avaliação global da edificação. A envoltória representa $30 \%$ e complementando o cálculo da avaliação, o sistema de condicionamento de ar representa 40\%. Os resultados das avaliações são utilizados para classificação da edificação em níveis de eficiência energética que vão desde o nível A (mais eficiente) ao nível E (menos eficiente), previstos na Etiqueta Nacional de Conservação de Energia (ENCE).

A avaliação da eficiência energética do sistema de iluminação, pelo RTQ-C, pode ser realizada pelo método das áreas ou o método das atividades. Para este estudo foi escolhido o método das áreas, que avalia de forma conjunta os ambientes da edificação.

Os parâmetros para avaliação da eficiência energética do sistema de iluminação estão descritos na Tabela 2. Conforme a Instrução Normativa MPOG/SLTI no 2/2014 (MPOG, 2014), os projetos de edificações com área construída acima de $500 \mathrm{~m}^{2}$ devem possuir nível A de eficiência pelo ENCE. Nos casos de retrofit, a orientação é de níveis parciais A para os sistemas de iluminação e de acondicionamento de ar, salvo inviabilidade técnica ou econômica devidamente justificada.

Tabela 2. Critérios de classificação dos níveis de eficiência energética.

\begin{tabular}{|c|c|c|c|c|}
\hline \multirow[t]{2}{*}{$\begin{array}{l}\text { Itens da portaria do } \\
\text { INMETRO }\end{array}$} & \multicolumn{4}{|c|}{$\begin{array}{l}\text { Limite máximo aceitável de densidade de potência de } \\
\text { iluminação (DPIL) para o nível de eficiência pretendido } \\
\left(\mathrm{W} / \mathrm{m}^{2}\right)\end{array}$} \\
\hline & Nível A & Nível B & Nível C & Nível D \\
\hline Biblioteca & 12,7 & 14,6 & 16,5 & 18,4 \\
\hline \multicolumn{5}{|l|}{ Pré-requisitos para classificação } \\
\hline Divisão de circuitos & Sim & Sim & Sim & - \\
\hline Contribuição da luz natural & Sim & Sim & - & - \\
\hline $\begin{array}{l}\text { Desligamento automático do } \\
\text { sistema de iluminação }\end{array}$ & Sim & - & - & - \\
\hline
\end{tabular}

Fonte: Adaptado de INMETRO (2010).

A determinação do nível de eficiência do sistema de iluminação é calculada através de um número representativo do sistema de iluminação, chamado de EqNumDPI. Para cada nível de eficiência há uma relação numérica equivalente (Tabela 3).

Tabela 3. Equivalente numérico para cada nível de eficiência.

\begin{tabular}{|l|c|}
\hline EqNumDPI & Classificação \\
\hline$\geq 4,5$ a 5 & A \\
\hline$\geq 3,5$ a $<4,5$ & B \\
\hline$\geq 2,5$ a $<3,5$ & C \\
\hline$\geq 1,5$ a $<2,5$ & D \\
\hline$<1,5$ & E \\
\hline
\end{tabular}

Fonte: INMETRO (2010).

A classificação final da eficiência energética do sistema de iluminação dependerá dos pré-requisitos serem atendidos para cada ambiente. 0 cálculo do EqNumDPI é a média 
ponderada das potências de iluminação considerando o EqNum de cada ambiente. A Tabela 4 descreve a forma de cálculo para o caso da biblioteca do Câmpus B.

Tabela 4. Equivalente numérico para cada nível de eficiência.

\begin{tabular}{|c|c|c|c|}
\hline & Acervo & Leitura & Geral \\
\hline \multicolumn{4}{|c|}{ Classificação de eficiência energética do sistema de iluminação - Biblioteca - Câmpus B } \\
\hline Área por ambiente $\left(\mathrm{m}^{2}\right)$ & 112 & 279 & 390 \\
\hline Potência de iluminação por ambientes (W) & 1152 & 3520 & 4672 \\
\hline \multicolumn{4}{|c|}{ Limites de potência de iluminação por nível de classificação (W) } \\
\hline Nível A por ambiente & 1417 & 3538 & 4955 \\
\hline Nível B por ambiente & 1629 & 4067 & 5696 \\
\hline Nível C por ambiente & 1841 & 4596 & 6437 \\
\hline Nível D por ambiente & 2053 & 5126 & 7178 \\
\hline EqNumDPI por ambiente & & & 5 \\
\hline \multicolumn{4}{|l|}{ Pré-requisitos } \\
\hline Divisão dos circuitos & Sim & Sim & \multirow{4}{*}{ - } \\
\hline Contribuição da luz natural & Não & Não & \\
\hline $\begin{array}{l}\text { Desligamento automático do sistema de } \\
\text { iluminação }\end{array}$ & Sim & Não & \\
\hline EqNumDPI por pré-requisitos & 3 & 3 & \\
\hline EqNum calculado considerando pré-requisitos & \multicolumn{3}{|c|}{3,0} \\
\hline $\begin{array}{l}\text { Nível de eficiência energética do sistema de } \\
\text { iluminação }\end{array}$ & \multicolumn{3}{|c|}{ Nível C } \\
\hline
\end{tabular}

O cálculo do EqNumDPI por ambiente ficou em 5, classificando a edificação como nível A. Entretanto quando se aplicam os pré-requisitos, os ambientes de acervo e leitura obtiveram o equivalente 3. Calculando-se a média ponderada entre as potências de iluminação que possuem EqNumDPI igual a 3 e as que possuem EqNumDPI igual a 5, resultou no EqNumDPI final de 3, que representa eficiência energética do sistema de iluminação nível C.

\section{Iluminação natural}

Nesta etapa da pesquisa, os dados de projeto das 14 bibliotecas foram reunidos para criação da maquete eletrônica. 0 software escolhido para criar os modelos foi o Google Sketchup, versão 8.0.

A modelagem 3D dos ambientes das bibliotecas baseou-se nas medidas das plantas baixas, cortes e elevações que compõem o projeto arquitetônico executivo, na escala 1:1.

Além do projeto da edificação, o modelo 3D previu a implantação dos edifícios do entorno ao objeto de estudo para que fossem consideradas suas influências de sombreamento. A maior parte das informações sobre orientação das fachadas e edificações vizinhas foi consultada nos planos diretores de cada Câmpus. Já as informações de coordenadas geográficas foram consultadas no Google Maps.

Nos modelos 3D foram coletados dados construtivos relevantes para apoio na análise da incidência da radiação solar direta no interior das edificações. Em outra tabela foram coletados dados de: coordenadas geográficas; área de piso dos ambientes internos; azimute de cada fachada; área envidraçada de cada fachada.

A simulação da entrada da radiação solar direta no interior da edificação foi realizada pela função shadow do software Google Sketchup, utilizando como parâmetros o 
dia 21 de junho (dia de inverno) e o dia 22 de dezembro (dia de verão). Nas simulações foi registrada a área de piso que recebeu radiação solar direta do Sol, considerando intervalos de 30 minutos durante todo o horário de funcionamento das bibliotecas. A Figura 4 mostra um exemplo de coleta de dados da biblioteca do Câmpus A. Todas as áreas expostas à radiação solar direta foram contabilizadas em uma planilha somando cada área atingida diretamente pelo Sol.

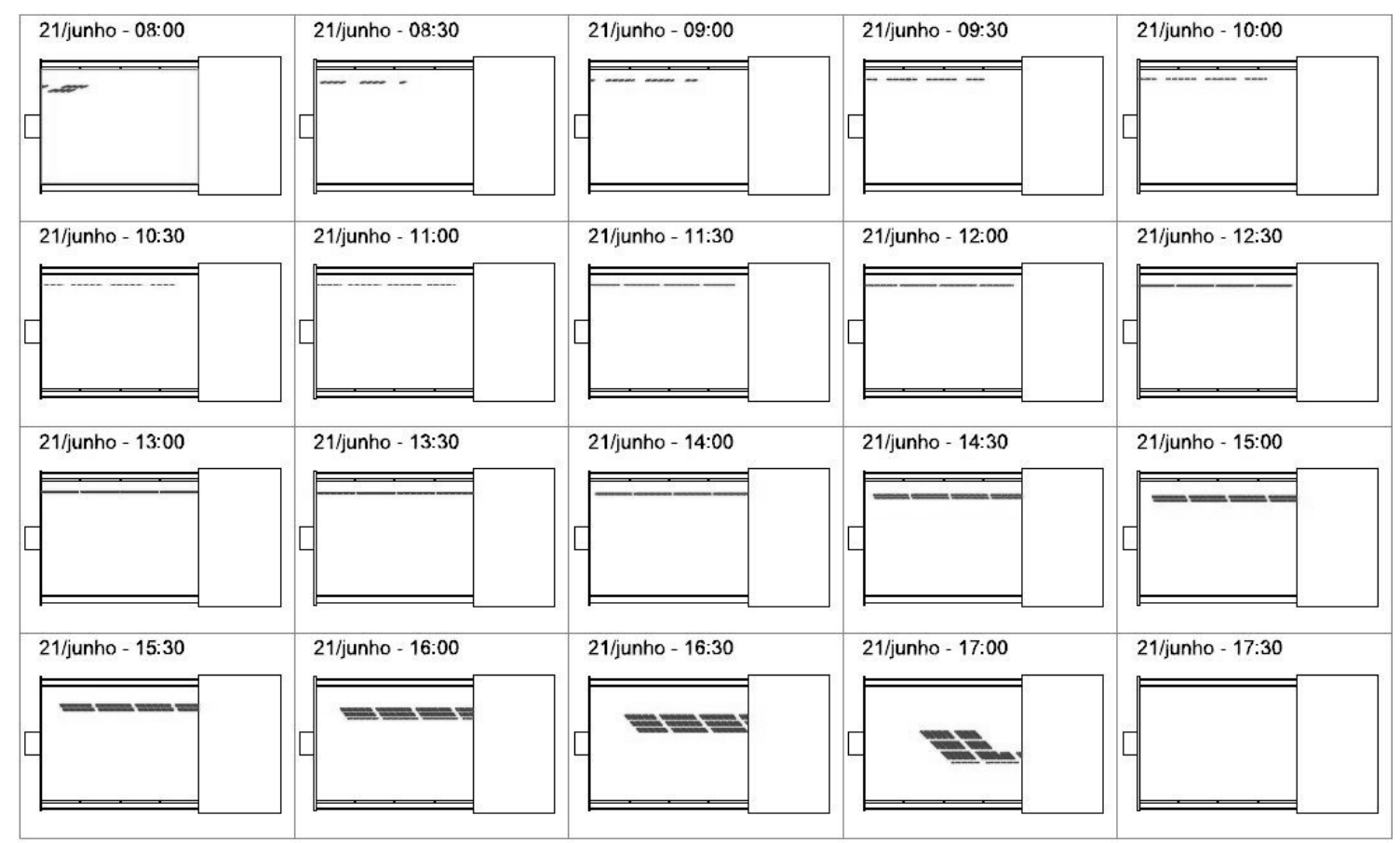

Figura 4. Áreas de insolação no inverno - Biblioteca do Câmpus A.

Para complementar as informações da quantidade de radiação solar direta no ambiente, foi necessário buscar dados sobre a intensidade da radiação solar que cada fachada está exposta, considerando um dia de céu claro. Tais dados foram registrados através de consulta ao software Luz do Sol versão 1.1 (Roriz, 1995). 0 software possui vários módulos de funcionamento, e neste estudo foi escolhido o módulo de radiação solar, uma vez que as informações de energia oriunda da radiação solar direta é um fator importante para a análise dos resultados.

\section{Resultados e discussão}

Os estudos de caso das bibliotecas foram realizados em duas frentes, uma relacionada à iluminação artificial e outra relacionada à iluminação natural, mais precisamente na incidência da radiação solar direta no interior das bibliotecas.

\section{Análise da iluminação artificial}

$\mathrm{Na}$ análise do desempenho da iluminação artificial, verificou-se que somente $32,14 \%$ dos ambientes analisados atendem a condição da iluminância mínima e 10,71\% atendem a condição de uniformidade da iluminação, conforme descrito na Tabela 5. 
Tabela 5. Desempenho da iluminação artificial.

\begin{tabular}{|l|c|c|c|}
\hline \multirow{2}{*}{ Itens verificados } & \multicolumn{3}{|c|}{ Porcentagem de ambientes atendidos pela NBR } \\
\cline { 2 - 4 } & Acervos & Leituras & Geral \\
\hline Atende a iluminância média mantida & $57,14 \%$ & $7,14 \%$ & $32,14 \%$ \\
\hline Possui uniformidade & $7,14 \%$ & $14,29 \%$ & $10,71 \%$ \\
\hline Evita ofuscamento & $57,14 \%$ & $57,14 \%$ & $57,14 \%$ \\
\hline Atende a reprodução de cores & $71,43 \%$ & $71,43 \%$ & $71,43 \%$ \\
\hline
\end{tabular}

O resultado final do sistema de iluminação artificial, após a avaliação dos ambientes de acervo e leitura das bibliotecas, considerando os parâmetros da NBR ISO/CIE 8995-1 e do RTQ-C, estão apresentados na Figura 5. Nesta figura, as duas linhas tracejadas representam os valores de iluminância mínima para os ambientes de leitura, 500 lux, e acervo, 200 lux. Na sequência da esquerda para a direita, as barras horizontais em cada biblioteca representam o nível de eficiência energética do sistema de iluminação, a iluminância média da área de acervo e a iluminância média da área de leitura.

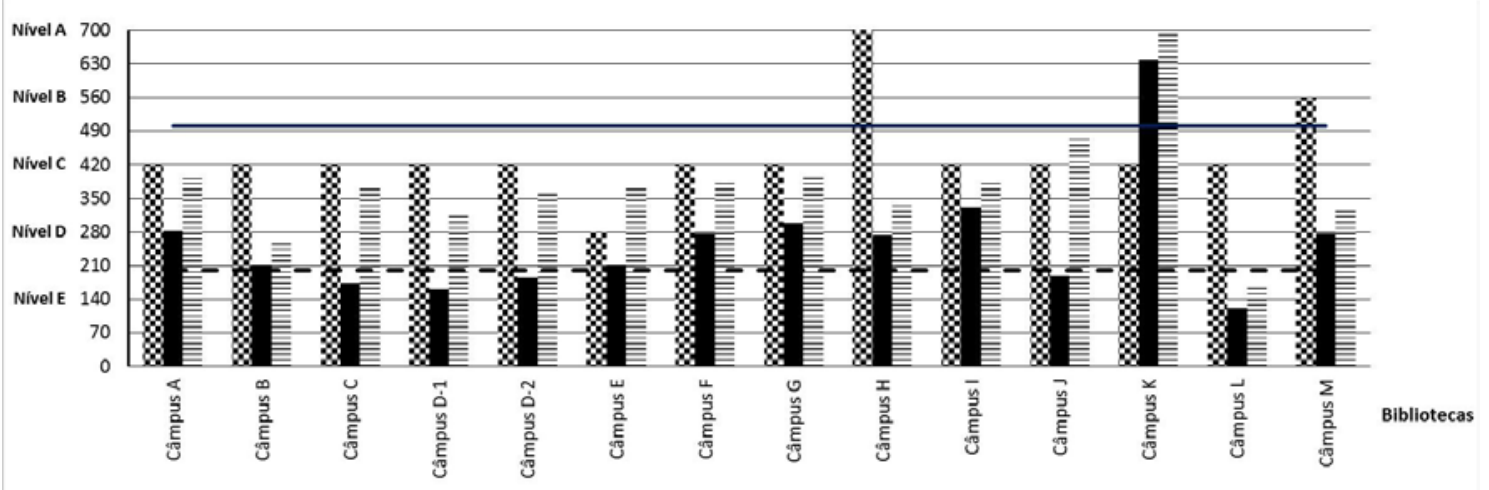

SWO Nivel de eficiência

Figura 5. Comparativo da iluminâncias das bibliotecas e seus níveis de eficiência.

Constatou-se que a biblioteca do Câmpus $\mathrm{H}$ foi a única que obteve classificação $\mathrm{A}$ no sistema de iluminação. Já a biblioteca do Câmpus K foi a única que obteve desempenho acima dos parâmetros mínimos da NBR ISO/CIE 8995-1, fato este que pode ser explicado devido o sistema de iluminação possuir projeto mais recente e sua depreciação ainda não ser significativa.

Durante o processo de compilação dos dados coletados do sistema de iluminação artificial, verificou-se, na Figura 6, que mais sete bibliotecas poderiam ser classificadas em nível A, caso atendessem aos pré-requisitos estabelecidos pelo RTQ-C. Neste cenário, a biblioteca do Câmpus K seria classificada com nível A de eficiência do sistema de iluminação e atenderia as iluminâncias mínimas prescritas por norma. 


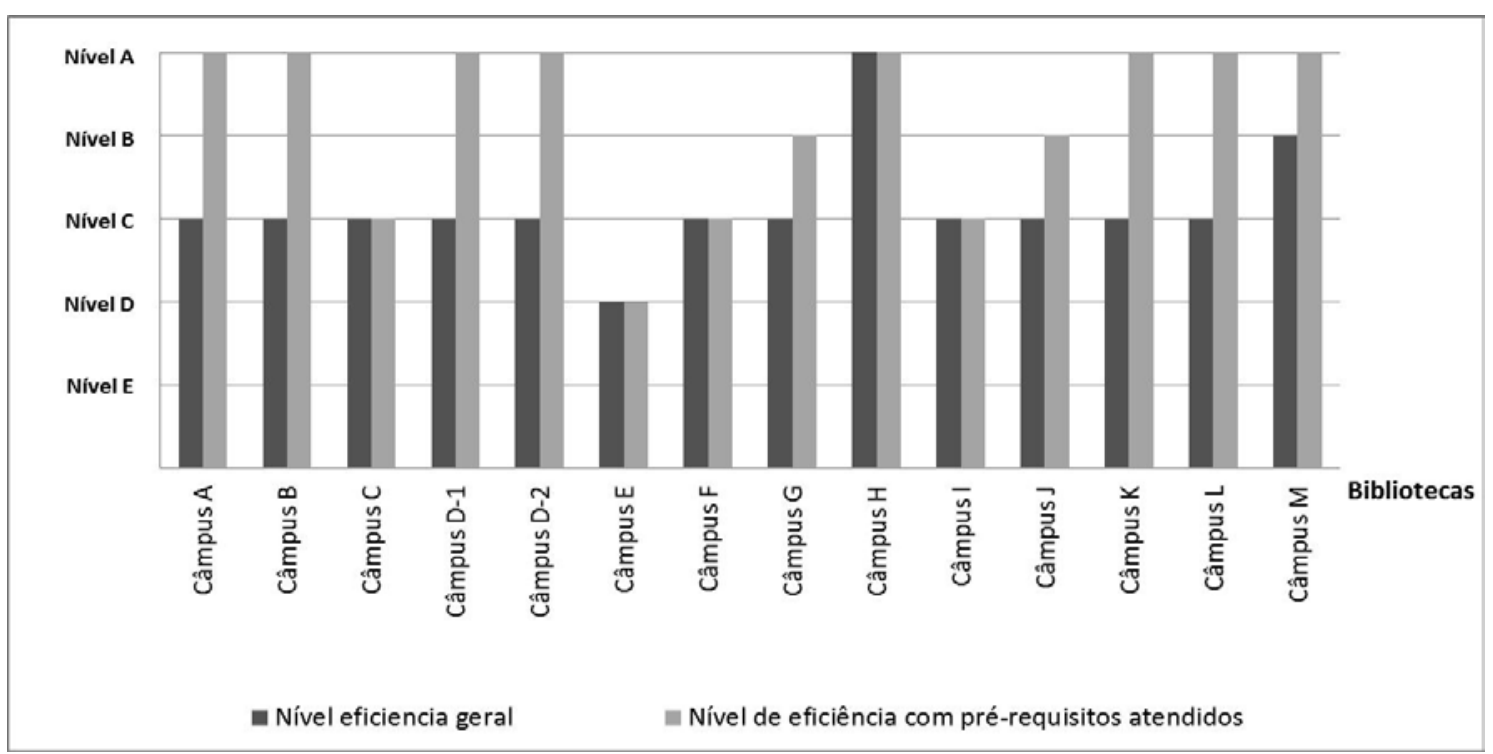

Figura 6. Comparativo da eficiência das bibliotecas com os pré-requisitos atendidos.

\section{Análise da radiação solar direta no interior da edificação}

As simulações da insolação nas maquetes geraram os dados da Tabela 6, onde estão classificadas por ordem decrescente as piores situações verificadas. As porcentagens de área de piso representam a quantidade de área de piso que recebe luz direta do Sol desde o horário de abertura da biblioteca $(8: 00 \mathrm{~h})$ até o pôr do Sol. 0 valor de $100 \%$ seria equivalente à condição de incidência da luz do Sol em toda área da biblioteca durante o período de funcionamento, o qual o Sol se faz presente.

Tabela 6. Classificação das bibliotecas quanto à incidência de radiação solar direta.

\begin{tabular}{|c|c|c|c|}
\hline \multicolumn{4}{|c|}{ Luz direta no interior das bibliotecas } \\
\cline { 3 - 4 } Classificação & \multirow{2}{*}{ Bibliotecas } & Inverno & Verão \\
\hline 1 & & $11,20 \%$ & $4,52 \%$ \\
\hline 2 & Câmpus K & $6,58 \%$ & $2,33 \%$ \\
\hline 3 & Câmpus I & $6,22 \%$ & $4,69 \%$ \\
\hline 4 & Câmpus D-1 & $4,38 \%$ & $1,55 \%$ \\
\hline 5 & Câmpus J & $3,62 \%$ & $3,60 \%$ \\
\hline 6 & Câmpus M & $3,03 \%$ & $1,21 \%$ \\
\hline 7 & Câmpus F & $2,50 \%$ & $0,01 \%$ \\
\hline 8 & Câmpus E & $2,10 \%$ & $2,03 \%$ \\
\hline 9 & Câmpus G & $1,76 \%$ & $1,45 \%$ \\
\hline 10 & Câmpus D-2 & $1,29 \%$ & $0,00 \%$ \\
\hline 11 & Câmpus A & $1,09 \%$ & $0,20 \%$ \\
\hline 12 & Câmpus H & $0,67 \%$ & $0,16 \%$ \\
\hline 13 & Câmpus B & $0,34 \%$ & $0,61 \%$ \\
\hline 14 & Câmpus L & $0,22 \%$ & $0,72 \%$ \\
\hline
\end{tabular}


Diante da análise da incidência da radiação solar no interior das edificações, a biblioteca do Câmpus K apresentou uma situação mais preocupante dentre as demais bibliotecas, muito embora o seu desempenho da iluminação artificial seja a melhor situação encontrada.

Os valores de área atingida pela luz direta do Sol obtidas através das simulações não trazem informação da intensidade que a radiação solar possui. As janelas recebem a radiação de acordo com a orientação das fachadas da edificação e os horários do dia, neste sentido, criou-se um gráfico onde é mostrado o valor da área atingida pela luz do Sol e o valor da intensidade da radiação solar. Essas duas informações em conjunto auxiliam a análise dos ambientes com a finalidade de evitar a entrada da radiação solar direta na edificação. As análises foram realizadas em horários que as intensidades da radiação solar provocada pela luz direta são mais elevadas, bem como na fachada em que a luz entra.

Contudo, os valores inseridos nos gráficos possuem intensidades e unidades de medida diferentes, uma vez que são grandezas distintas. Para que fossem comparados no mesmo gráfico, as unidades foram convertidas para valores unitários adimensionais. As medidas de área definidas por metro quadrado $\left(\mathrm{m}^{2}\right)$ foram divididas por um padrão de área, chamado de base, resultando em um valor por unidade (p.u.). 0 mesmo procedimento foi adotado para a radiação solar definido por watt hora por metro quadrado $\left(\mathrm{Wh} / \mathrm{m}^{2}\right)$.

Para a biblioteca do Câmpus K, por exemplo, a base de cálculo para a unidade adimensional da área foi $90 \mathrm{~m}^{2}$ e da radiação solar $500 \mathrm{Wh} / \mathrm{m}^{2}$. As Figuras 7 e 8 indicam que no inverno a entrada da luz direta do Sol acontece o dia todo, principalmente no início da manhã. No verão o comportamento é inverso, a entrada de luz direta ocorre no período da tarde. A proteção solar sugerida deve atuar no:

- Inverno:

12:00 h às $17: 30 \mathrm{~h}$ - fachada 2 (oeste);

08:00 h às 16:30 $\mathrm{h}$ - fachada 3 (norte).

- Verão:

08:00 h às 09:30 h - fachada 3 (norte);

12:30 h às 19:00 $\mathrm{h}$ - fachada 2 (oeste);

14:30 h às 19:00 $\mathrm{h}$ - fachada 1 (sul).

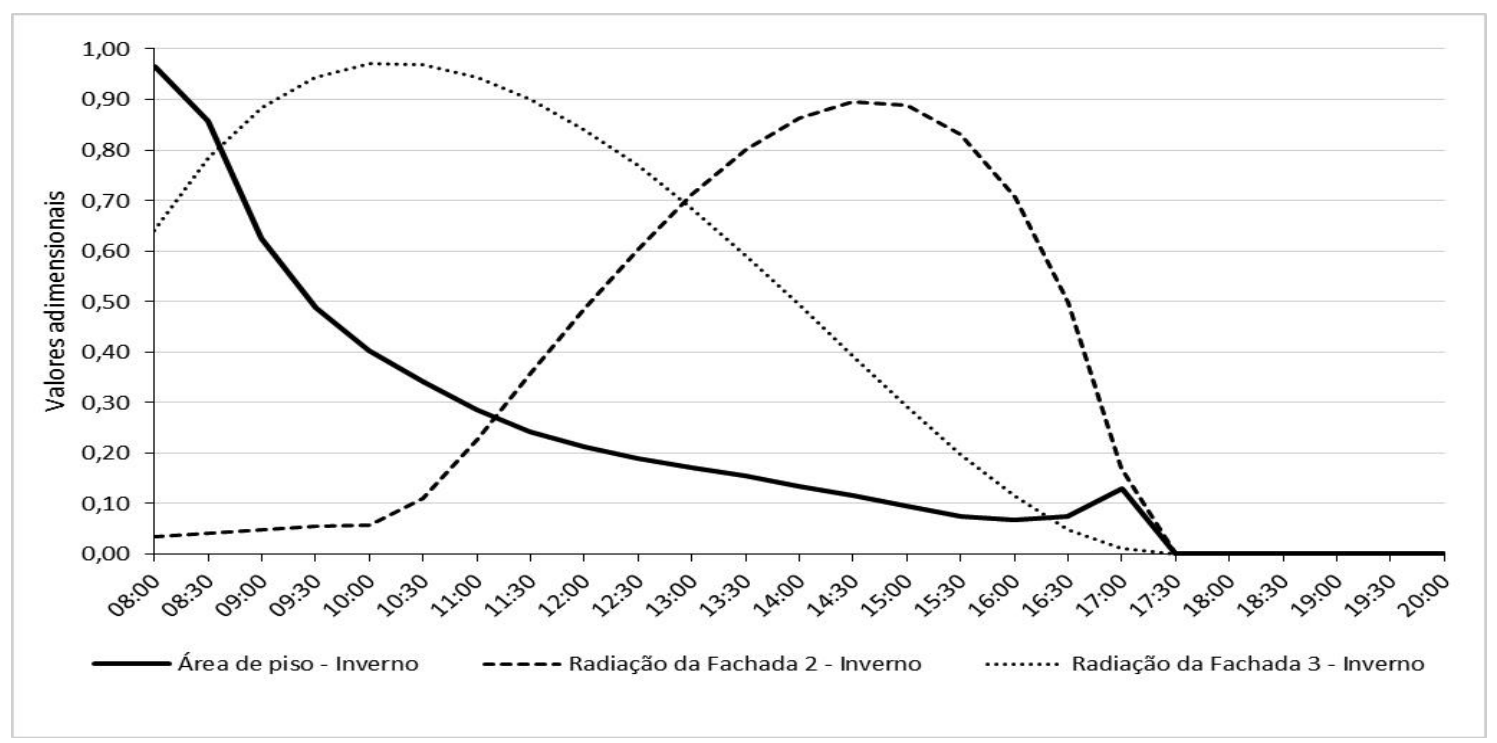

Figura 7. Radiação solar direta na biblioteca do Câmpus K - inverno. 


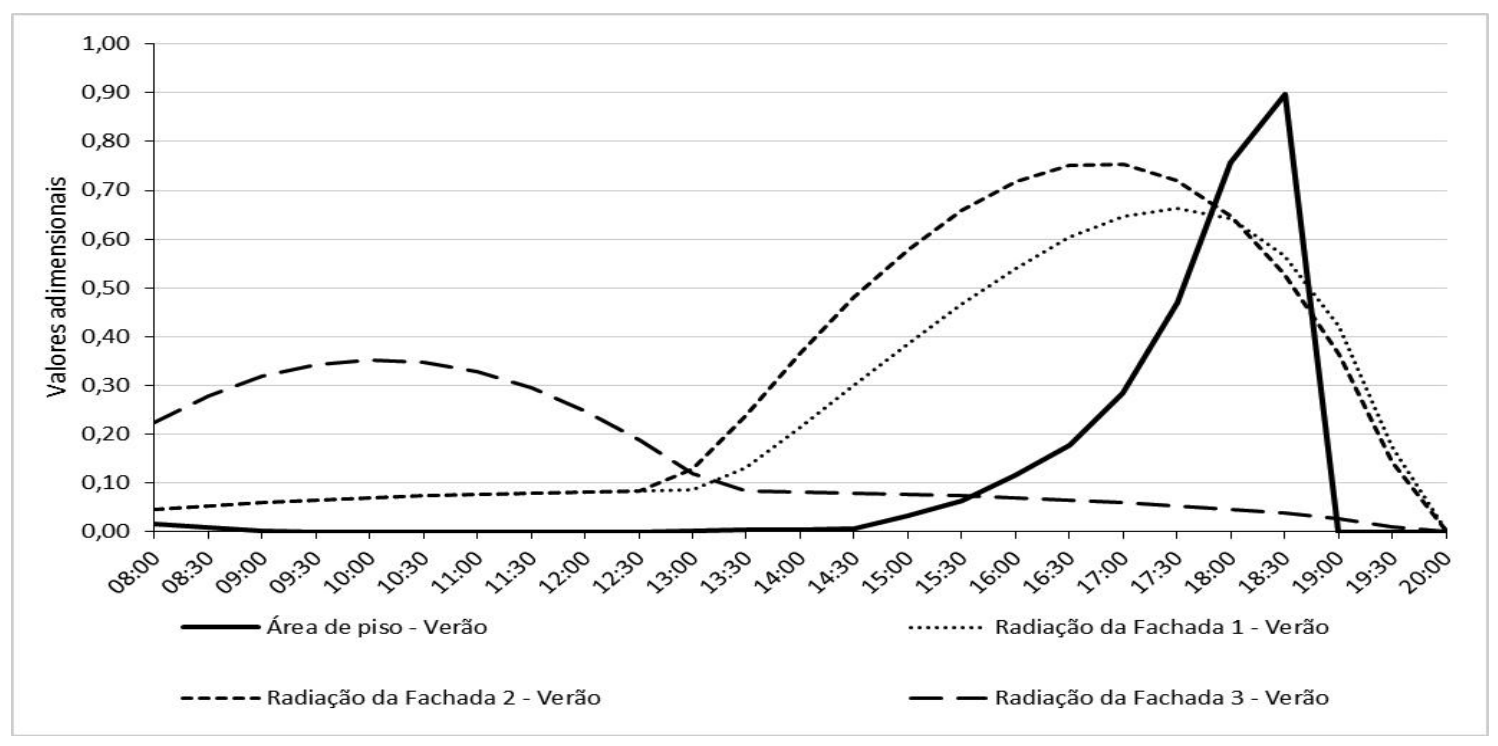

Figura 8. Radiação solar direta na biblioteca do Câmpus K - verão.

\section{Retrofit}

Durante a análise de dados, duas soluções de retrofit foram simuladas nas bibliotecas dos Câmpus E e K, a primeira devido ao baixo desempenho do sistema de iluminação artificial e a segunda devido a radiação solar direta excessiva em seu interior.

Utilizando o software Dialux evo 5.0, a simulação da iluminação artificial atingiu os requisitos da NBR ISO/CIE 8995-1, ao mesmo passo que elevou para o nível A de eficiência pelo RTQ-C. As alterações realizadas nos cálculos do novo sistema de iluminação foram:

a) Altura de montagem das luminárias passou de 2,60m para 3,00m, essa alteração diminui as áreas de sombreamento e aumenta a uniformidade na iluminação;

b) Nas áreas de estantes e circulações, substituição das luminárias de lâmpadas fluorescentes tubulares de $2 \times 32 \mathrm{~W}$ com aletas para luminárias de lâmpadas fluorescente compactas de $26 \mathrm{~W}$, diminuindo assim a potência da iluminação na área de acervo.

c) Nas áreas de leitura, substituição das luminárias de lâmpadas fluorescentes tubulares de $2 \times 32 \mathrm{~W}$ com aletas para luminárias de lâmpadas fluorescente tubulares de $2 \times 28 \mathrm{~W}$, pois este tipo de lâmpada possui um fluxo luminoso maior;

d) $\quad 0$ conceito do projeto foi alterado de um arranjo flexível das mesas de trabalho para um sistema de áreas de trabalho delimitadas, considerando-se assim a iluminância mantida de 500 lux para a área de trabalho e 300 lux no entorno imediato;

e) Nas baias de estudo individuais, a iluminação da tarefa foi prevista com luminária de mesa com comando individual e integrado ao mobiliário. Este tipo de iluminação não é considerado nos cálculos da densidade de potência de iluminação do RTQ-C.

f) Todas as luminárias próximas às janelas possuem comando independente, separadas por setores, para aproveitamento da luz natural.

Na Figura 9, os resultados das curvas isolux mostram 500 lux de iluminância sobre as áreas das mesas de estudo e 300 lux no entorno imediato. Nas áreas de acervo a 
iluminância está acima dos 200 lux, as áreas indicadas na figura com índices de 5 a 10 lux são os topos das estantes. A condição de uniformidade também foi assegurada conforme orientações de norma.

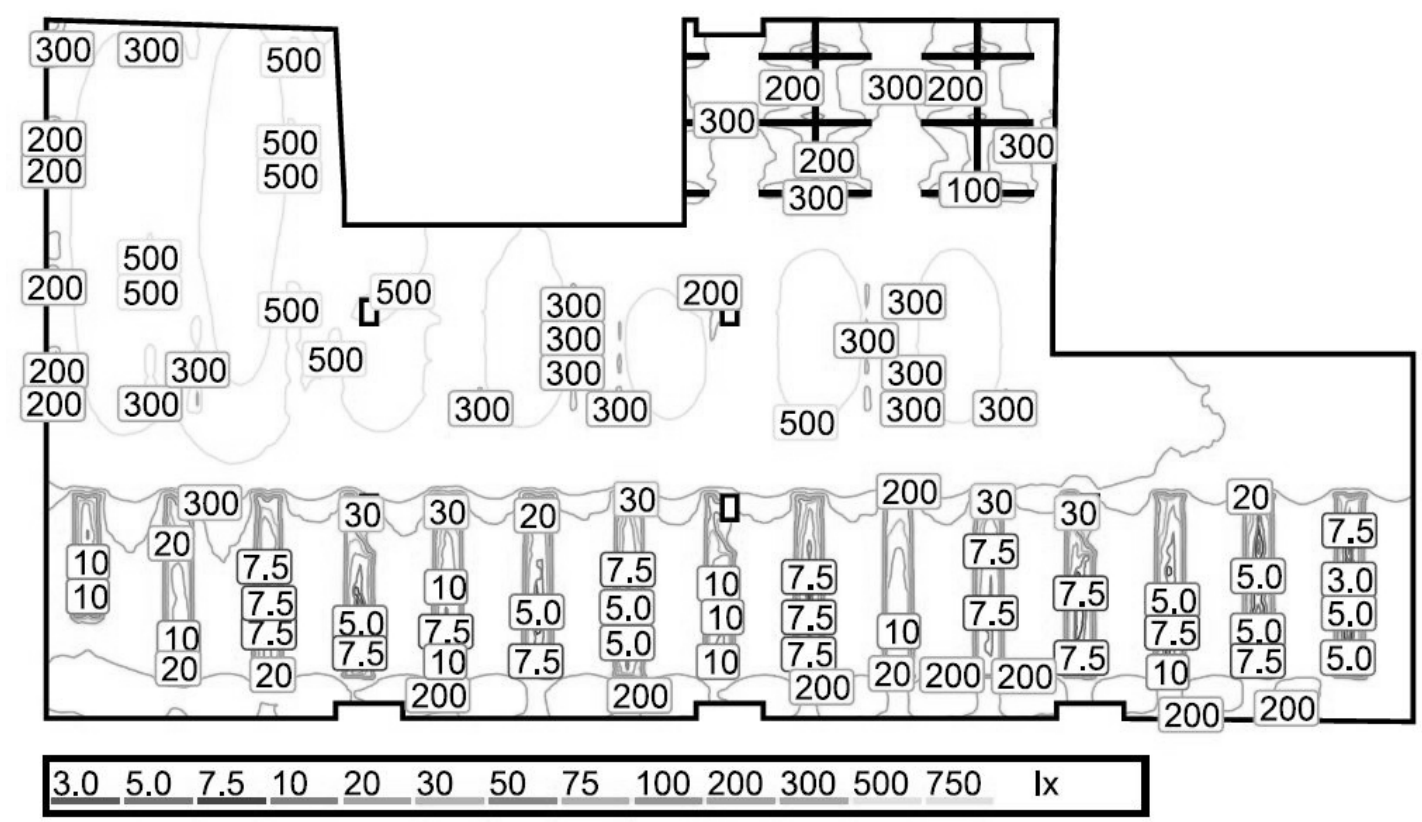

Figura 9. Simulação DIALUX - acervo e leitura da biblioteca do Câmpus E.

A solução escolhida para melhorar o conforto visual durante o dia e também possibilitar o uso da iluminação natural para contribuir com o sistema de iluminação foi o uso de prateleiras de luz em conjunto com brises fixos. Este tipo de solução apresenta bom sombreamento aliado à utilização da luz natural e proteção ao ofuscamento (Laar, 2001), além de melhorar o desempenho térmico da edificação.

A simulação foi realizada com auxílio do Google Sketchup, onde foram implantadas brises nas janelas com placas de $15 \mathrm{~cm}$ de profundidade, altura de $2 \mathrm{~cm}$ com inclinação de $15^{\circ}$ e $10 \mathrm{~cm}$ de afastamento uma da outra. A função dos brises é complementada com prateleiras de luz na parte superior das janelas, nas dimensões de 1,90 m largura, avançando no lado externo da edificação e 1,66 m internamente. A prateleira foi definida a $2,92 \mathrm{~m}$ de altura para harmonizar com a janela existente, deixando uma folha de vidro acima dela para a entrada da luz na parte superior.

A Figura 10 mostra os resultados encontrados para simulação da implantação de brises nas janelas no verão, no horário das $17 \mathrm{~h} 30 \mathrm{~min}$, com incidência da luz direta antes e depois da instalação das proteções na fachada 1 (sul). 

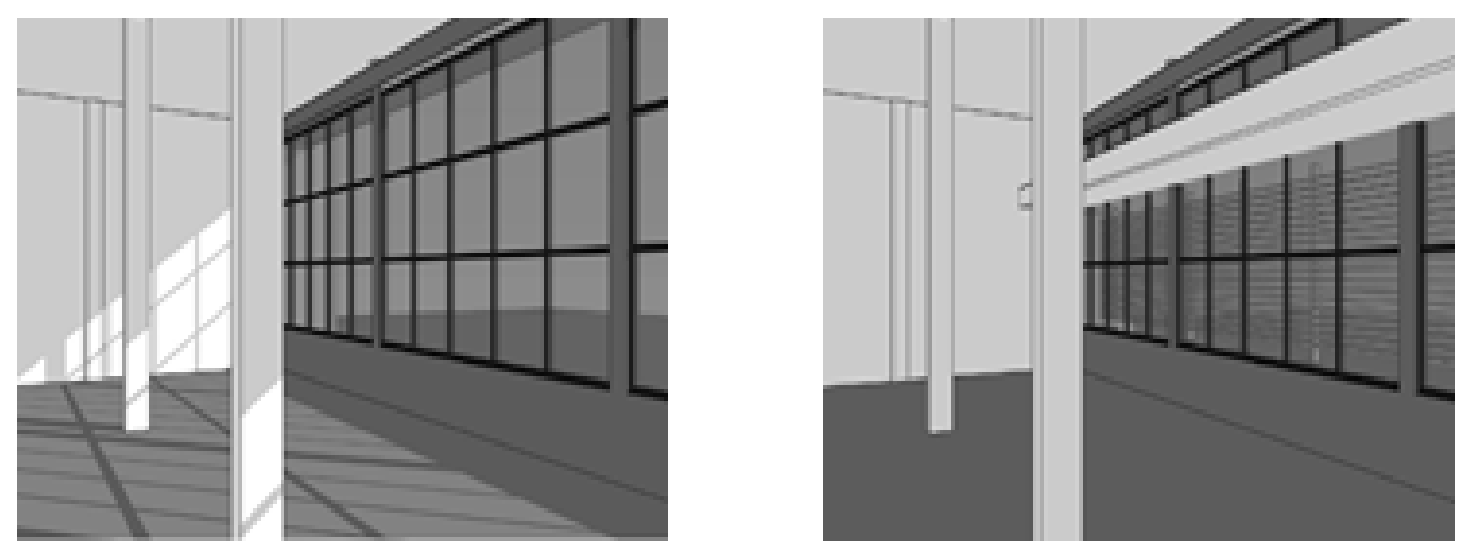

Figura 10. Entrada da luz direta no verão sem proteção e com proteção.

Os resultados desta simulação apresentaram um bloqueio de $100 \%$ da radiação solar incidente no interior da edificação sem comprometer a contribuição da luz difusa. Durante a simulação da entrada da radiação solar direta, verificou-se que os horários próximos ao amanhecer e ao entardecer são de difícil controle. Apesar da radiação nestes horários apresentar níveis de energia relativamente baixos, tal situação pode provocar ofuscamento. 0 uso de modelos 3D para analisar a edificação durante o processo de elaboração de projetos poderia evitar as edificações recebessem níveis tão elevados de radiação solar direta em seu interior.

\section{Conclusão}

O estudo investigou as condições de iluminação de quatorze bibliotecas da UTFPR, distribuídas em quatorze municípios diferentes e em três zonas climáticas distintas. Observou-se que a maioria dos sistemas de iluminação das bibliotecas analisadas pode ser adaptada visando à obtenção de melhor desempenho. Oito das 14 bibliotecas obtiveram classificação A no nível de eficiência do sistema de iluminação, considerando os pré-requisitos do RTQ-C atendidos. Já o desempenho da iluminância mantida calculada nos ambientes foi menos favorável. Na área de acervo oito bibliotecas atingiram média acima de 200 lux e na área de leitura apenas uma biblioteca atingiu a média de 500 lux.

As análises comprovaram que, exceto a biblioteca do Câmpus $\mathrm{K}$, as demais bibliotecas necessitam aumentar a média da iluminância em pelo menos um ambiente, ao passo que a densidade de potência de iluminação deve ser diminuída ou mantida. Verificou-se que as bibliotecas universitárias estudadas em que há funcionamento noturno, o projeto do sistema de iluminação deve estar compatibilizado com o layout do mobiliário e dos ambientes. Sem esta vinculação, o projeto do sistema de iluminação não consegue atender as condições da NBR ISO/CIE 8995-1 e estar classificada como nível A de eficiência pelo RTQ-C. Os principais problemas que contribuíram com o baixo desempenho foram: as incompatibilidades entre o layout das luminárias e o layout das áreas de trabalho; a depreciação do sistema de iluminação; e o uso de lâmpadas com baixo fluxo luminoso, aquém do previsto em projeto.

A análise da incidência direta da radiação solar no interior das bibliotecas resultou em 11 bibliotecas sobre as quais há incidência maior no inverno se comparado ao verão. Esta condição é ideal para aquecer o ambiente no inverno, entretanto, observou-se que em todos os ambientes estudados a incidência da luz solar direta deve ser controlada. 0 conforto visual dos usuários e a preservação do acervo são os principais fatores que justificam o controle da radiação solar direta nas bibliotecas analisadas. 
A metodologia utilizada para a verificação do sistema de iluminação artificial se mostrou eficiente, possibilitando analisar o sistema com os parâmetros na norma NBR ISO/CIE 8995-1, simultaneamente vislumbrando um enquadramento nível A de eficiência, conforme os parâmetros do RTQ-C.

Em relação à radiação solar direta, a utilização de maquetes eletrônicas se mostrou ferramenta adequada de verificação de edificações existentes e de planejamento de novas edificações, principalmente em razão da facilidade de inserção de elementos externos no entorno da edificação, que possam interferir na disponibilidade da luz natural. 0 estudo do comportamento da luz direta do Sol em fachadas, bem como no interior das edificações pode ser realizado na etapa de projeto. Durante o processo de análise dos modelos das bibliotecas constatou-se que a maioria das bibliotecas possui boa área envidraçada, possibilitando a entrada da luz natural em seus ambientes. Já a incidência da luz direta no interior das bibliotecas deve ser controlada de forma mais eficiente, evitando-se o uso das cortinas e blackouts e sendo sugerida a utilização de prateleiras de luz juntamente com brises.

\section{Conflito de interesses}

Os autores declaram não haver conflito de interesses.

\section{Referências}

ABNT - Associação Brasileira de Normas Técnicas. NBR ISO/CIE 8995-1: Iluminação de ambientes de trabalho Parte 1: Interior. Rio de Janeiro: ABNT, 2013.

Amaral, S. A.; Fortes, L. S. Cuidados com o ambiente físico das bibliotecas universitárias: preocupação supérflua ou necessária? Anais do XIII Seminário Nacional de Bibliotecas Universitárias, Natal, UFRN, 2004.

CLIR - Council on Library and Information Resources. No brief candle: Reconceiving research libraries for the 21st Century. Washington, DC: CLIR, 2008. Disponível em: <http://www.clir.org/pubs/reports/pub142/pub142.pdf>. Acesso em: 12 out. 2014.

Danieleski, C. B.; Oliveira, M. F.; Medeiros, D. R. Avaliação do desempenho da luz natural em ambientes residenciais. PARC - Pesquisa em Arquitetura e Construção, v. 10, e019012, 2019. https://doi.org/10.20396/parc.v10i0.8652735

Dias, M. M. K.; Pires, D. Formação e desenvolvimento de coleções de serviços de informação. São Carlos: EdUFSCar, 2003.

Fernandes, J.T. Código de obras e edificações do DF: Inserção de conceitos bioclimáticos, conforto térmico e eficiência energética. Brasília: Universidade de Brasília, 2009. (Dissertação de mestrado).

Frota, A. B. Geometria da insolação. São Paulo: Geros, 2004.

Ghisi, E. Desenvolvimento de uma metodologia para retrofit em sistemas de iluminação: estudo de caso na Universidade Federal de Santa Catarina. Florianópolis: Universidade Federal de Santa Catarina, 1997. (Dissertação de mestrado).

INMETRO - Instituto Nacional de Metrologia, Normalização e Qualidade Industrial. Portaria no 372, de 17 de setembro de 2010. Requisitos técnicos da qualidade para o nível de eficiência energética de edifícios comerciais, de serviços e públicos. Disponível em: <http://www.inmetro.gov.br/legislacao/rtac/pdf/RTAC001599.pdf>. Acesso em: 12 out. 2014. 
Krausse, B.; Cook, M.; Lomas, K. Environmental performance of a naturally ventilated city centre library. Energy and Buildings, v. 39, p. 792-801, 2007. https://doi.org/10.1016/ j.enbuild.2007.02.010

Laar, M. Light and shadow: An analysis of daylighting and shadowing systems for the tropics. Proceedings of the PLEA 2001 - The 18th International Conference on Passive and Low Energy Architecture, Florianópolis, 2001.

Leitão, B. J. M. Avaliação qualitativa e quantitativa numa biblioteca universitária. Rio de Janeiro: Interciência, 2005. v. 1.

Lucker, J. K. The evolution of research library buildings. Computer Methods and Programs in Biomedicine, v. 44, p. 155-160, 1994. https://doi.org/10.1016/01692607(94)90108-2

Mendes, N.; Westphal, F. S.; Lamberts, R.; Cunha Neto, J. A. B. Uso de instrumentos computacionais para análise do desempenho térmico e energético de edificações no Brasil. Ambiente Construído, v. 5, n. 4, p. 47-68, 2005.

MPOG - Ministério do Planejamento, Orçamento e Gestão. Instrução Normativa MPOG/SLTI no 2, de 04 de junho de 2014. Dispõe sobre regras para a aquisição ou locação de máquinas e aparelhos consumidores de energia pela Administração Pública Federal direta, autárquica e fundacional, e uso da Etiqueta Nacional de Conservação de Energia (ENCE) nos projetos e respectivas edificações públicas federais novas ou que recebam retrofit. Disponível em: <http://www.comprasgovernamentais.gov.br/ paginas/instrucoes-normativas/instrucao-normativa-no-2-de-4-de-junho-de-2014>.

Acesso em: 12 out. 2014.

Neufert, E. Arte de projetar em Arquitetura. 18. ed. São Paulo: Gustavo Gili, 2013.

Ogden, S. (Ed.). 14 a 17 Meio ambiente. 2. ed. Rio de Janeiro: Projeto Conservação Preventiva em Bibliotecas e Arquivos: Arquivo Nacional, 2001. Disponível em: <https://www.arqsp.org.br/wp-content/uploads/2017/08/14_17.pdf>. Acesso em: 15 jul. 2014.

Osterhaus, W. K. E. Discomfort glare assessment and prevention for daylight applications in office environments. Solar Energy, v. 79, n. 2, p. 140-158, 2005. https://doi.org/ 10.1016/j.solener.2004.11.011

Roriz, M. Luz do Sol: um software para estimar o calor e a luz provenientes do Sol. Anais do III Encontro Nacional e I Encontro Latino-Americano sobre Conforto no Ambiente Construído, Gramado, 1995.

Severo, H. M. A.; Scalcon, T. H. W.; Salbego, A. G. Modelagem em 3D: uso do sketchup no desenvolvimento de projetos de engenharia. Anais do Salão Internacional de Ensino, Pesquisa e Extensão, da Universidade Federal do Pampa, Bagé-RS, 2012. Disponível em: <http://seer.unipampa.edu.br/index.php/siepe/article/view/2014>. Acesso em: 16 set. 2014.

Shane, J. Positioning your library for solar (and financial) gain: Improving energy efficiency, lighting, and ventilation with primarily passive technique. The Journal of Academic Librarianship, v. 38, n. 2, p. 115-122, 2012. https://doi.org/10.1016/ j.acalib.2012.01.004

Silva, A. M. S.; Salbego, A. G.; Silva, T. M. V.; Bordoli, V. S. Uso do software Sketchup para estudos de orientação solar em projetos de engenharia. Anais do Salão Internacional de Ensino, Pesquisa e Extensão, da Universidade Federal do Pampa, Bagé-RS, 2013. 
Disponível em: <http://seer.unipampa.edu.br/index.php/siepe/article/view/6047>. Acesso em: 12 out. 2014.

Sousa, M. N. P. O. Padrões em projetos arquitetônicos de bibliotecas públicas. Campinas: Universidade Estadual de Campinas, 2012. (Dissertação de mestrado).

Souza, D. F. Iluminação natural e artificial em bibliotecas da UNICAMP: diagnóstico e recomendações. Campinas: Universidade Estadual de Campinas, 2010. (Dissertação de mestrado).

Vianna, N. S.; Gonçalves, J. C. S. Iluminação e Arquitetura. São Paulo: Geros, 2007. 